\title{
Investigation of Public Libraries Managed by Outsourcing: A Study Focusing on Library Usage, Opening Days, and Directors' Librarian Qualifications and Workloads
}

\author{
Yuhiro Mizunuma ${ }^{*}$, Keita Tsuji ${ }^{\dagger}$
}

\begin{abstract}
Public libraries in Japan were managed by local governments for a long time. However, in 2003, organizations including private enterprises, NPOs and foundations took over their management with the introduction of an outsourcing system, namely the 'designated administrator system'. The question of whether this outsourcing system is appropriate for public libraries is a subject of current debate, wherein many argue that it is inappropriate. To provide basic data for this discussion, we conducted a cross-sectional and time series analysis on almost all public libraries in Japan focusing on library usage, number of open days, and director qualifications and workload. The results show that the opening days and percentage of certified directors of public libraries managed by the outsourcing system ('outsourcing libraries') was more than those managed by local governments ('direct management libraries'), whereas the number of Inter-Library Loan (ILL)-borrowings and the number of ILL-lending were more in direct management libraries than in outsourcing libraries. It was also shown that the library usage and open days, as well as the number of certified directors increased after the introduction of the outsourcing system.
\end{abstract}

Keywords: designated administrator system, library management, public libraries.

\section{Introduction}

Public libraries in Japan were managed by local governments for a long time. However, in 2003, organizations including private enterprises, NPOs and foundations took over their management with the introduction of an outsourcing system, namely the 'designated administrator system'. Although the number of public libraries managed under this outsourcing system (henceforth 'outsourcing libraries') is increasing, many argue that it is an inappropriate system for public libraries because of concerns over the degradation of services, the decrease in staff expertise, and the decline in the level of cooperation between libraries. Nevertheless, few studies have examined the performance of outsourcing libraries using large-scale comprehensive samples.

* Surugadai University, Saitama, Japan

$\dagger$ University of Tsukuba, Ibaraki, Japan 
Within this context, we used almost all Japanese public libraries as subjects and conducted two types of analysis: (1) cross-sectional analysis and (2) time series analysis, with a focus on library usage, open days, and the director. For the cross-sectional analysis, we analyzed the differences between outsourcing libraries and 'traditional' libraries managed directly by the local government (henceforth 'direct management libraries') at a certain point in time. More specifically, we obtained statistics on library usage, open days, and the qualifications and workload of the directors, and compared statistics drawn from approximately 300 outsourcing libraries with those from approximately 2,000 direct management libraries (the exact number varies depending on the investigation). Those data were obtained from the 2012 and 2015 editions of Statistics on Libraries in Japan [1], published by the Japan Library Association. For the time series analysis, we analyzed changes in statistics from approximately 200 libraries before and after they introduced outsourcing. This data were obtained from the 2003 to 2015 editions of Statistics on Libraries in Japan [1]. The following five types of statistics were considered to determine library usage: (a) gate count, (b) number of loans, (c) number of books borrowed through Inter-Library Loan (ILL), (d) number of books loaned through ILL, and (e) number of reference transactions. We also examined the number of open days in a year and evaluated whether the libraries were open on holidays. We also analyzed whether the directors held librarian certifications and were working as full-time or equivalent employees.

In this paper, we first provide a brief overview of the designated administrator system in Japan in section 2, and the related surveys and studies in section 3 . In section 4, we describe the method of this study. We then provide the results of this study in section 5 and present a discussion of our findings in section 6. Finally, we summarize and conclude the paper in section 7.

\section{Brief Overview of the Designated Administrator System}

The 'designated administrator system' was introduced in Japan through the revision of the Local Autonomy Act in 2003. The new system allows organizations organizations including private enterprises, NPOs and foundations to manage public facilities, which include public libraries. Then, organizations including private enterprises, NPOs and foundations took over public library management with the introduction of the new outsourcing system. The local government is supposed to revise the municipal ordinance based on a resolution of the local council in order to introduce the system to public facilities. It was also established by the Local Autonomy Act that the procedure for designating, the scope of operations, and designated period must be described in the revised municipal ordinance.

The number of public libraries managed under this outsourcing system has been increasing from 2003. However, as mentioned previously, there are many views on applying this outsourcing system to libraries. For example, the Japan Library Association [2] argued that it was inappropriate to apply this system to public libraries, while the Japan Association for Promotion of Social Education [3] also argued that the system would infringe on the residents' right to learn. There are a lot of negative comments such as that outsourcing may degrade the quality of library services provided, decrease the expertise of librarians, and reduce cooperation with other libraries [2][3][4]. 


\section{Related Studies}

Within the context stated above, some librarians working in outsourcing libraries reported changes after the introduction of the outsourcing system [5][6]. Some researchers and related organizations also clarified the changes after the introduction of the new system. For example, Maeda [7], the Japan Library Association [8], and Koyama and Nagata [9] used questionnaires to investigate the merits of outsourcing libraries or the changes that occurred after outsourcing systems were introduced. These investigations ascertained that outsourcing systems improved the quality of services provided, increased the number of open hours, and increased library usage.

Some studies have focused on the changes in the statistics after the introduction of the outsourcing system in specific regions. Yamaguchi [10] clarified the changes after the introduction of the outsourcing system by focusing on the number of loans and the prevailing financial situation in eight public libraries in Tachikawa-city. In his study, Yamaguchi concluded that the number of loans had increased only in five libraries after the introduction of the outsourcing system, and noted that the expenditure incurred through outsourcing tended to increase. Kambayashi [11] studied the changes after the introduction of the outsourcing system in Ota-ku, specifically focusing on the number of users enrolled, the loans and reservations made, and the employment costs incurred. This study found that although the number of users enrolled, loans, and reservations had increased, the financial resources saved by cutting down on a full-time worker was not used towards the improvement of library services. Shiomi [12] searched a list of municipalities whose libraries had introduced the outsourcing system (106 municipalities) and prepared a list of the top 10\% municipalities based on the number of loans (132 municipalities) made and found that only 10 municipalities appeared in both lists. However, the above-mentioned studies (based on questionnaires and statistical data) used relatively small samples. On the other hand, in this study, we conducted a statistical analysis based on large and allencompassing data in order to provide a wholesome picture.

Mouri and Ohba [13] conducted a comparative study similar to our study, concerning certified directors in outsourcing and direct management libraries. They noted the rate of certified directors in outsourcing libraries and in direct management libraries using the government survey conducted in 2011 (The Survey on Social Education by the Ministry of Education, Culture, Sports, Science and Technology). The results show that directors in outsourcing libraries are more likely to have librarian certifications as opposed to those in direct management libraries. We conducted a similar analysis using the 2012 and 2015 editions of Statistics on Libraries in Japan, and also conducted a time series analysis.

If we do not limit the data to that on outsourcing libraries, we can find many studies that conducted time series analyses using statistical data on libraries. For example, there are studies concerning certified directors [14][15], reference transactions [16][17], and open days[18] of libraries in Japan. Tsuji[19] investigated the kind of learning commons that leads to an increase in library usage. In this study, the increase rates were calculated based on the means of gate counts, the number of loans made, and the number of reference transactions (the data were obtained from Statistics on Libraries in Japan), and identified some of the elements of learning commons that may increase the gate counts and reference transactions. As described above, many studies show the actual situation of libraries using statistical data such as Statistics on Libraries in Japan, and there are studies that conduct time series analysis in order to clarify the changes that take place with an event (for example, installing learning commons) such as Tsuji. Therefore, we conducted cross-sectional 
and time series analysis using Statistics on Libraries in Japan in order to clarify the actual situation of libraries with a focus on outsourcing.

\section{Method}

We conducted two kinds of analysis: cross-sectional analysis and time series analysis. In the following subsections, we first explain each method, following which we explain the classification of sample libraries.

\subsection{Cross-sectional Analysis}

Through a cross-sectional analysis, we investigated the differences between outsourcing and direct management libraries at a certain point in time. We first selected the 2015 edition of Statistics on Libraries in Japan because it was the most recent edition available when we began our research. This edition listed the FY 2014 gate count, number of loans, and open days per year. Information on working holidays and whether the directors held library certifications and worked full-time was also included as of April 2015. We took the 3,253 public libraries listed in the Statistics on Libraries in Japan as our sample. We then classified the sample libraries as either outsourcing or direct management libraries based on The Report on Public Libraries Managed by the Designated Administrator System (2015)[20]. This source includes a list of libraries managed under the designated administrator system. Thus, we identified libraries listed in the report as outsourcing libraries and all others as direct management libraries. We also used the 2012 edition of Statistics on Libraries in Japan to improve the reliability of the data. We took the 3,224 public libraries listed in the Statistics on Libraries in Japan as our sample and classified them as either outsourcing or direct management libraries based on The Report on Public Libraries Managed by the Designated Administrator System (2012) [20].

We selected the following five usage statistics as indicators of library usage: (1) gate count, (2) number of loans made, (3) number of books borrowed through ILL[21], (4) number of books loaned through ILL, and (5) number of reference transactions[22]. For the cross-sectional analysis, we considered the library size by dividing the usage statistics by the population of the municipality where the library was located, and then calculated the usage statistics per resident for each library (because larger libraries tend to have more use as, in general, they have many residents, that is, users, around them). We compared the mean and median of usage between outsourcing and direct management libraries. We also compared the mean and median of the numbers of open days between both kinds of libraries. Further, we also compared the number of working holidays and whether directors held library certifications and worked full-time.

\subsection{Time Series Analysis}

In the time series analysis, we investigated changes after the introduction of the outsourcing system. We used 3,811 public libraries listed in the annual Statistics on Libraries in Japan from the 2005 to 2015 editions as our sample, because the 2005 edition includes the data on the first outsourcing library and the 2015 edition is the most recent edition available. 
We classified the libraries as either outsourcing or direct management libraries based on The Report on Public Libraries Managed by the Designated Administrator System (2016) [20] because it was the latest edition available. This report also indicated the time when each library introduced outsourcing. To track library usage and open days, we calculated the increase rate $(I R)$ for each category. The $I R$ is defined as follows:

$$
\operatorname{IR}(\%)=\frac{A_{2}-B_{2}}{B_{2}} \times 100(\%)
$$

where $B_{2}$ is the mean in the two years before the introduction of outsourcing and $A_{2}$ is the mean of the usage statistics in the two years after its introduction. For example, the Chiyoda Library introduced outsourcing in 2007. Therefore, we calculated the mean of the previously mentioned usage statistics in 2005 and 2006. There were 280,216 and 259,788 gate counts in 2005 and 2006, respectively. Therefore, the mean of gate counts in these two years was $((280,216+259,788) / 2=) 270,002$. Similarly, the mean of gate counts in the two years following the introduction of outsourcing was 921,464 (for years 2008 and 2009). Therefore, the $I R$ of gate counts for Chiyoda Library is ((921,464 $270,002) / 270,002 \times 100=241.3 \%$. We assume that if the $I R$ is greater than zero, library usage or open days increased after the introduction of outsourcing.

To identify whether they were open on holidays and whether the directors held librarian certifications and worked full-time, we first measured the patterns over four years for each library (two years before the transition to outsourcing and two years after). For example, Chiyoda Library's status of directors holding library certifications in 2005, 2006, 2008, and 2009 were No, No, Yes, and Yes, respectively. Therefore, the pattern is NNYY (N means No and Y means Yes). There were 16 possible patterns, (1) NNNN, (2) NNNY, (3) NNYY,..., (16) YYYY. We calculated the rate of each pattern for outsourcing libraries and assumed that if the pattern was NNYY, a non-certified director was assigned until the introduction of outsourcing and a certified director was assigned after outsourcing. If the pattern was YYNN, a certified director was assigned until the introduction of outsourcing and a non-certified director was assigned after outsourcing.

We also calculated the $I R \mathrm{~s}$ and the rate of each pattern in the direct management libraries, comparing them with those of the outsourcing libraries. Since there was no comparable point in time when the direct management libraries underwent a change in their system, we calculated the $I R$ s and the rate of each pattern for every year from 2005 to 2015. The statistical data we analyzed and each analytical method are summarized in Table 1.

\subsection{Classification of Sample Libraries}

We used the public libraries listed in the Statistics on Libraries in Japan as our sample libraries. As mentioned previously, we classified them as either outsourcing or direct management libraries based on the Report on Public Libraries Managed by the Designated Administrator System.

We also classified the libraries as either main libraries or annexes, and based on the type of municipality served, into (1) prefectures, (2) ordinance-designated cities, (3) Tokyo special wards, (4) cities other than ordinance-designated ones, and (5) towns or villages[23]. The classification was based on Statistics on Libraries in Japan. We also classified outsourcing libraries based on the corporate form of the administrator into the following categories: (a) private enterprise, (b) NPO, (c) public corporation, or (d) other organization, 
Table 1: Our analysis subject and each analytical method

\begin{tabular}{|c|c|c|c|}
\hline \multirow{2}{*}{ Statistical data } & & \multicolumn{2}{|c|}{ Analytical Method } \\
\hline & & Cross-sectional & Time series \\
\hline \multirow[t]{5}{*}{ Usage } & Gate count & \multirow{6}{*}{$\begin{array}{l}\text { We compared } \\
\text { the mean and } \\
\text { median }\end{array}$} & \multirow{6}{*}{$\begin{array}{l}\text { We calculated } \\
\text { the } I R\end{array}$} \\
\hline & Number of loans & & \\
\hline & Number of books borrowed through ILL & & \\
\hline & Number of books loaned through ILL & & \\
\hline & Number of reference transactions & & \\
\hline \multirow[t]{2}{*}{ Open days } & The numbers of open days & & \\
\hline & Openings during holidays & \multirow{2}{*}{$\begin{array}{l}\text { We compared } \\
\text { the rate }\end{array}$} & \multirow{2}{*}{$\begin{array}{l}\text { We measured } \\
\text { four years of } \\
\text { patterns }\end{array}$} \\
\hline Directors & $\begin{array}{l}\text { Whether directors held library certifications } \\
\text { Whether directors worked full-time }\end{array}$ & & \\
\hline
\end{tabular}

using Report on Public Libraries Managed by the Designated Administrator System. Next, we identified the top three predominant administrators (i.e. those managing the most libraries) using the Survey on the Introduction of the Designated Administrator System [24] conducted by the Government (Ministry of Internal Affairs and Communications). Table 2 shows the total number of libraries in each category in our sample. The predominant administrators are also shown in Table 2. In this table, 'OL' means outsourcing libraries, and 'DML' means direct management libraries.

Table 2: Sample libraries

\begin{tabular}{|c|c|c|c|c|c|c|c|}
\hline & \multicolumn{4}{|c|}{ Cross-sectional } & \multicolumn{2}{|c|}{ Time series } \\
\hline & & \multicolumn{2}{|c|}{2012 edition } & \multicolumn{2}{|c|}{2015 edition } & \multirow{2}{*}{ OL } & \multirow{2}{*}{ DML } \\
\hline & & $\mathrm{OL}$ & DML & $\mathrm{OL}$ & DML & & \\
\hline (All Libraries) & & 299 & 2,925 & 431 & 2,822 & 489 & 3,322 \\
\hline \multirow[t]{2}{*}{ Main vs.Annex } & Main libraries & 116 & 1,235 & 154 & 1,211 & 172 & 1,579 \\
\hline & Annexes & 183 & 1,690 & 277 & 1,611 & 317 & 1,743 \\
\hline \multirow{5}{*}{$\begin{array}{l}\text { Types of } \\
\text { municipality }\end{array}$} & Prefectural library & 2 & 59 & 4 & 56 & 5 & 60 \\
\hline & Ordinance-designated cities & 36 & 243 & 55 & 226 & 56 & 232 \\
\hline & Tokyo special wards & 76 & 149 & 99 & 124 & 107 & 124 \\
\hline & Other cities & 146 & 1,917 & 216 & 1,865 & 261 & 2,004 \\
\hline & Towns and villages & 39 & 557 & 57 & 551 & 60 & 902 \\
\hline \multirow{4}{*}{$\begin{array}{l}\text { Corporate } \\
\text { form of } \\
\text { administrator }\end{array}$} & Private enterprise & 207 & - & 323 & - & 381 & - \\
\hline & NPO & 36 & - & 40 & - & 41 & - \\
\hline & Public corporation & 47 & - & 52 & - & 53 & - \\
\hline & Other organisation & 9 & - & 16 & - & 14 & - \\
\hline \multirow{3}{*}{$\begin{array}{l}\text { Predominant } \\
\text { administrators }\end{array}$} & A Company & 98 & - & 104 & - & 105 & - \\
\hline & B Company & 9 & - & 17 & - & 17 & - \\
\hline & C Foundation & 11 & - & 11 & - & 11 & - \\
\hline
\end{tabular}

\section{Results}

In this section, we present the results concerning library usage, open days, and director statistics. 


\subsection{Results of Library Usage}

The results of the cross-sectional analysis concerning (1) gate count, (2) number of loans, (3) number of books borrowed through ILL, (4) number of books loaned through ILL, and (5) number of reference transactions, for both outsourcing and direct management libraries are provided in Table 3. As in Table 2, 'OL' refers to outsourcing libraries, and 'DML' refers to direct management libraries in the tables below. ' $\mathrm{N}$ ' represents the number of libraries, the asterisks in the 'Mean' column represent significant differences based on Welch's test and those in the 'Median' column represent the significant differences based on the Brunner-Munzel test. The asterisks ' $*$ ' and ' $* *$ ' in these columns represent the differences at 0.05 and 0.01 significance levels, respectively. '2012 edition' and ' 2015 edition' present the results based on the 2012 edition of Statistics on Libraries in Japan and the 2015 edition of the book, respectively.

Based on the number of books borrowed through ILL in the 2012 edition, the mean and median of direct management libraries ( 0.0143 and 0.0046 , respectively) were significantly higher than those of outsourcing libraries ( 0.0093 and 0.0031 , respectively). Based on those in the 2015 edition, the mean and median of direct management libraries (0.0169 and 0.0054 , respectively) were significantly higher than those of outsourcing libraries ( 0.0095 and 0.0024 , respectively). Further, for the number of books lent through ILL in the 2012 edition, the mean and median of direct management libraries $(0.0084$ and 0.0027 , respectively) were higher than those of outsourcing libraries $(0.0069$ and 0.0019 , respectively). Based on those in the 2015 edition, the mean and median of direct management libraries ( 0.0090 and 0.0032 , respectively) were significantly higher than those of the outsourcing libraries ( 0.0061 and 0.0016 , respectively). These results suggest that direct management libraries borrow more and lend more library materials from and to other libraries than do outsourcing libraries.

The IRs of individual library usage are provided in Table 4. This table shows the means and medians of IRs (by percentage) for outsourcing and direct management libraries. The means and medians of $I R \mathrm{~s}$ for usage in outsourcing libraries were all more than zero, whereas the median of $I R$ for gate count in direct management libraries was less than zero $(-2.6 \%)$. The means of the $I R \mathrm{~s}$ for four instances of usage in outsourcing libraries were higher than the $I R \mathrm{~s}$ in direct management libraries. For example, the mean of the $I R$ for gate count in outsourcing libraries was $30.7 \%$ while that for direct management libraries was $6.6 \%$. In addition, the medians of the $I R \mathrm{~s}$ for all usages in outsourcing libraries were higher than those for direct management libraries. For example, the median of the $I R$ for the number of loans was $11.1 \%$ for outsourcing libraries, while that for direct management libraries was $0.6 \%$. These results suggest that library use tended to increase after the introduction of outsourcing.

Next, we look at the results for each type. As mentioned previously, we compared outsourcing and direct management libraries based on type (main libraries or annexes, the type of municipality served, corporate form of the predominant administrator, and the administrator). In studying main libraries, annexes, and the type of municipality served, we simply compared outsourcing and direct management libraries based on type. In studying the corporate form of the administrator and the administrator (A company, B company, and C Foundation), we compared each type of outsourcing library with all direct management libraries.

Tables 5 and 6 show the results of the cross-sectional analysis. Due to space constraints, we omitted the line if there was no significant difference observed in either the 2012 or the 
Table 3: Results of the cross-sectional analysis of library usage per capita

\begin{tabular}{|c|c|c|c|c|c|c|c|}
\hline & \multicolumn{3}{|c|}{2012 edition } & \multicolumn{3}{|c|}{2015 edition } \\
\hline & & $\mathrm{N}$ & Mean & Median & $\mathrm{N}$ & Mean & Median \\
\hline \multirow[t]{2}{*}{ Gate count } & OL & 253 & 1.600 & $0.707 * *$ & 381 & 1.534 & 0.563 \\
\hline & DML & 2,074 & 1.281 & 0.610 & 2,149 & 1.204 & 0.584 \\
\hline \multirow[t]{2}{*}{ Number of loans } & OL & 272 & 2.671 & $1.516 * *$ & 417 & 2.253 & 1.015 \\
\hline & DML & 2,725 & 2.281 & 1.167 & 2,629 & 2.158 & 1.149 \\
\hline Number of & OL & 261 & 0.0093 & 0.0031 & 385 & 0.0095 & 0.0024 \\
\hline ILL-borrowings & DML & 2,279 & $0.0143 * *$ & $0.0046 * *$ & 2,150 & $0.0169 * *$ & $0.0054 * *$ \\
\hline Number of & OL & 222 & 0.0069 & 0.0019 & 333 & 0.0061 & 0.0016 \\
\hline ILL-lendings & DML & 1,926 & 0.0084 & 0.0027 & 1,879 & $0.0090 * *$ & $0.0032 * *$ \\
\hline \multirow{2}{*}{$\begin{array}{l}\text { Number of reference } \\
\text { transactions }\end{array}$} & OL & 254 & 0.0167 & $0.0068 *$ & 374 & 0.0186 & 0.0057 \\
\hline & DML & 2,097 & 0.0215 & 0.0054 & 2,089 & 0.0209 & 0.0064 \\
\hline
\end{tabular}

Table 4: Results of the time series analysis of library usage $(\operatorname{IR}(\%))$

\begin{tabular}{llrrr}
\hline & & $\mathrm{N}$ & Mean & Median \\
\hline Gate count & OL & 236 & 30.7 & 9.7 \\
& DML & 12,609 & 6.6 & -2.6 \\
\hline Number of loans & OL & 256 & 20.6 & 11.1 \\
& DML & 17,853 & 51.6 & 0.6 \\
\hline Number of ILL-borrowings & OL & 251 & 65.2 & 16.7 \\
& DML & 15,460 & 60.6 & 11.6 \\
\hline Number of ILL-lendings & OL & 198 & 782.2 & 43.1 \\
& DML & 12,278 & 152.0 & 14.2 \\
\hline Number of reference transactions & OL & 178 & 665.7 & 24.1 \\
& DML & 12,262 & 170.5 & 1.7 \\
\hline
\end{tabular}


2015 edition. In Table 6 , if there was ' $*$ ', the type's library usage was significantly higher than that of all direct management libraries, whereas if there was ' $\dagger$ ', the type's library usage was significantly lower than that of all direct management libraries. Table 6 shows outsourcing libraries managed by private enterprises. It showed that B Company and $\mathrm{C}$ Foundation had the same tendency with all libraries (i.e. libraries without type classification). These outsourcing libraries were significantly lower than direct management libraries in terms of the number of books borrowed and lent through ILL.

The mean and median IRs were over $0 \%$ among all types of outsourcing libraries except for the gate count in NPO and outsourcing libraries management by other organizations, and the number of books borrowed and lent through ILL in the outsourcing libraries managed by B Company. We can conclude that almost all types of libraries tend to experience increases in library usage after the introduction of outsourcing.

Table 5: Results of the cross-sectional analysis of library usage per capita (each type)

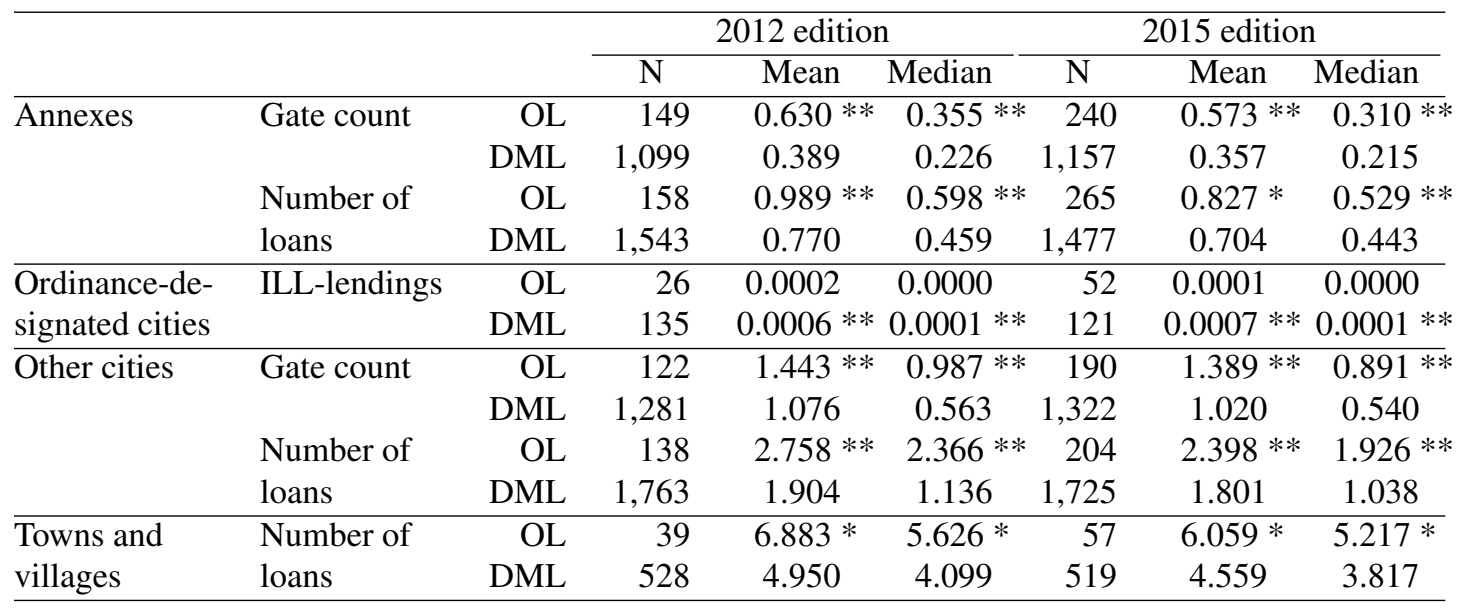

\subsection{Results of Open Days}

The results of the cross-sectional analysis of open days at outsourcing and direct management libraries are presented in Table 7. The results of whether they were open on holidays are presented in Table 8. In Table 8, the columns indicate the number of libraries that do not open on holidays and are not planning to ('No'); the number of libraries that are open on six holidays or less ('Yes $(=<6$ days)'); the number of libraries that are open on more than six holidays ('Yes ( $>=7$ days)'); and the number of libraries that are not open on holidays but are planning to remain open on holidays('Planning'). The double asterisks represent significant differences based on the Z-test for the proportions at 0.01 significance levels.

Table 7 shows that the means and medians for open days in the 2012 edition for outsourcing libraries (305.1 and 302.0, respectively) were significantly higher than those for direct management libraries (286.5 and 288.0, respectively). The means and medians for open days in the 2015 edition for outsourcing libraries (309.0 and 303.0, respectively) were significantly higher than those for direct management libraries (288.8 and 290.0, respectively), as well. 
Table 6: Results of the cross-sectional analysis of library usage per capita (each outsourcing type)

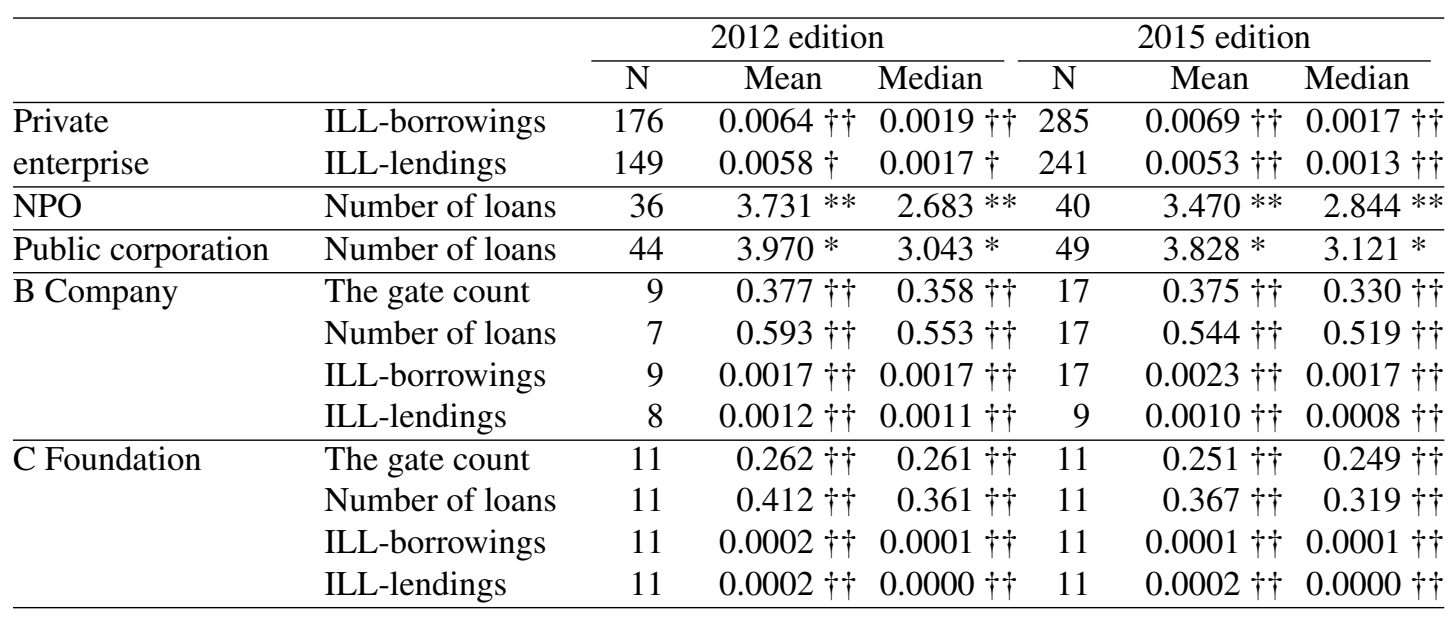

Table 8 shows that the rates of outsourcing libraries that remain open on more than six holidays, 'Yes ( $>=7$ days)', was $94.6 \%$ for the 2012 edition and $94.4 \%$ for 2015 edition, which were significantly higher than those of direct management libraries $(60.2 \%$ for 2012 edition and $64.7 \%$ for 2015 edition). The rates for 'No' and 'Yes $(=<6$ days)' for direct management libraries were significantly higher than those for outsourcing libraries. These results suggest that more outsourcing libraries tend to be open on holidays while direct management libraries tend to be closed on holidays or open on a lesser number of holidays.

The results of the time series analysis are presented in Tables 9 and 10. The $I R \mathrm{~s}$ of opening days are presented in Table 9, while the rates of each pattern concerning working on holidays are provided in Table 10. In Table 10, each character represents the status concerning working on holidays (i.e. a library is not open on holidays and is not planning to (' $\mathrm{N}$ '), open on six holidays or less (' 6 '), working on more than six holidays ('7'), or not working on holidays but is planning to ('P')) . The numbers in parentheses represent the number of libraries. For instance, 'NN77' for outsourcing libraries was ' $21.8 \%(78)$ ', which represented 78 outsourcing libraries that were not open on holidays in the two years before the introduction of the outsourcing system but were open on more than six holidays in the two years after introduction. Such libraries account for $21.8 \%$ of outsourcing libraries for all patterns. Due to space limitations, we omitted the line if there was no outsourcing library that corresponded to a pattern.

Table 9 shows that the means and medians of the IRs of opening days for outsourcing libraries were $4.5 \%$ and $2.8 \%$, respectively, whereas those for direct management libraries were $1.5 \%$ and $0.4 \%$, respectively. As mentioned before, $21.8 \%$ of outsourcing libraries were not open on holidays in the two years before the introduction of the outsourcing system but were open on more than six holidays in the two years after introduction, whereas only $2.5 \%$ of direct management libraries followed this pattern. These results suggest that the number of open days tended to increase after the introduction of outsourcing and more libraries began to open on holidays after the introduction of the outsourcing system.

Next, we look at the results for each type. Tables 11, 12,13 and 14 show the results of 
Table 7: Results of the cross-sectional analysis of open days

\begin{tabular}{|c|c|c|c|c|c|c|}
\hline & \multicolumn{3}{|c|}{2012 edition } & \multicolumn{3}{|c|}{2015 edition } \\
\hline & $\mathrm{N}$ & Mean & Median & $\mathrm{N}$ & Mean & Median \\
\hline $\mathrm{OL}$ & 281 & $305.1 * *$ & $302.0 * *$ & 415 & $309.0 * *$ & $303.0 * *$ \\
\hline DML & 2,806 & 286.5 & 288.0 & 2,738 & 288.8 & 290.0 \\
\hline
\end{tabular}

Table 8: Results of the cross-sectional analysis of whether libraries were open on holidays

\begin{tabular}{llrcccr}
\hline & & $\mathrm{N}$ & No & $\begin{array}{c}\text { Yes } \\
(=<6 \text { days })\end{array}$ & $\begin{array}{c}\text { Yes } \\
(>=7 \text { days })\end{array}$ & Planning \\
\hline 2012 edition & OL & 299 & $3.3 \%$ & $2.0 \%$ & $94.6 \% * *$ & $0.0 \%$ \\
& DML & 2,919 & $26.4 \% * *$ & $13.2 \% * *$ & $60.2 \%$ & $0.2 \%$ \\
\hline 2015 edition & OL & 431 & $4.2 \%$ & $1.4 \%$ & $94.4 \% * *$ & $0.0 \%$ \\
& DML & 2,818 & $22.6 \% * *$ & $12.4 \% * *$ & $64.7 \%$ & $0.2 \%$ \\
\hline
\end{tabular}

Table 9: Results of the time series analysis of open days (IR(\%))

\begin{tabular}{llrr}
\hline & \multicolumn{1}{c}{$\mathrm{N}$} & Mean & Median \\
\hline OL & 259 & 4.5 & 2.8 \\
DML & 18,272 & 1.5 & 0.4 \\
\hline
\end{tabular}

Table 10: Results of the time series analysis of whether libraries were open on holidays

\begin{tabular}{lrlrl}
\hline & \multicolumn{2}{c}{ OL } & \multicolumn{2}{c}{ DML } \\
\hline NNNN & $3.6 \%$ & $(13)$ & $24.7 \%$ & $(5,168)$ \\
NN66 & $0.3 \%$ & $(1)$ & $1.7 \%$ & $(351)$ \\
NN7N & $0.3 \%$ & $(1)$ & $0.0 \%$ & $(3)$ \\
NN77 & $21.8 \%$ & $(78)$ & $2.5 \%$ & $(521)$ \\
NNPP & $0.3 \%$ & $(1)$ & $0.1 \%$ & $(18)$ \\
N677 & $0.3 \%$ & $(1)$ & $0.3 \%$ & $(56)$ \\
N777 & $1.1 \%$ & $(4)$ & $1.4 \%$ & $(293)$ \\
NPNN & $0.3 \%$ & $(1)$ & $0.0 \%$ & $(1)$ \\
6NNN & $0.3 \%$ & $(1)$ & $0.4 \%$ & $(77)$ \\
6666 & $1.7 \%$ & $(6)$ & $9.6 \%$ & $(1,999)$ \\
6667 & $0.6 \%$ & $(2)$ & $0.9 \%$ & $(184)$ \\
6677 & $5.6 \%$ & $(20)$ & $2.5 \%$ & $(517)$ \\
6777 & $0.6 \%$ & $(2)$ & $1.6 \%$ & $(343)$ \\
7777 & $63.1 \%$ & $(226)$ & $47.1 \%$ & $(9,839)$ \\
P777 & $0.3 \%$ & $(1)$ & $0.3 \%$ & $(69)$ \\
\hline
\end{tabular}


the cross-sectional analysis of open days and whether libraries were open on holidays for each type. In Tables 13 and 14, we omitted the columns for 'open on six holidays or less' and 'not open on holidays but is planning to'.

Table 11 and Table 12 show that there was no type for which the mean and median of opening days were significantly lower than those of direct management libraries. Table 13 and Table 14 show there was no type under which the rate of libraries that worked on more than six holidays were significantly lower than those of direct management libraries. These tables also show that there were some types of outsourcing libraries whose mean and median of opening days were significantly higher than those of direct management libraries and rate of libraries that worked on more than six holidays were significantly higher than those of direct management libraries.

On the other hand, in the time series analysis, the mean and median $I R \mathrm{~s}$ for opening days were over $0 \%$ among all types of outsourcing libraries. We can thus conclude that all types of libraries tended to experience increases in the number of open days after outsourcing. For working on holidays, the rates of 'NN77' were over $0 \%$ among all types of outsourcing libraries, excluding the prefectural library and outsourcing libraries managed by $\mathrm{C}$ Foundation. The 'NN77' rate of both prefectural and outsourcing libraries managed by $\mathrm{C}$ Foundation were $0 \%$. On the other hand, there was no outsourcing library that corresponded to '77NN'.

Table 11: Results of the cross-sectional analysis of open days (each type)

\begin{tabular}{|c|c|c|c|c|c|c|c|}
\hline & \multicolumn{3}{|c|}{2012 edition } & \multicolumn{3}{|c|}{2015 edition } \\
\hline & & $\mathrm{N}$ & Mean & Median & $\mathrm{N}$ & Mean & Median \\
\hline \multirow[t]{2}{*}{ Main libraries } & $\mathrm{OL}$ & 111 & $296.2^{* *}$ & $295.0^{* *}$ & 145 & $304.3^{* *}$ & $299.0 * *$ \\
\hline & DML & 1,159 & 287.0 & 288.0 & 1,161 & 290.4 & 289.0 \\
\hline \multirow[t]{2}{*}{ Annexes } & OL & 170 & $311.0 * *$ & $315.5^{* *}$ & 270 & $311.5^{* *}$ & $309.5^{* *}$ \\
\hline & DML & 1,647 & 286.3 & 289.0 & 1,577 & 287.7 & 291.0 \\
\hline \multirow[t]{2}{*}{ Prefectural library } & $\mathrm{OL}$ & 2 & 325.0 & 325.0 & 4 & 316.3 & 321.5 \\
\hline & $\mathrm{DMl}$ & 57 & 287.2 & 289.0 & 56 & 294.3 & 293.0 \\
\hline \multirow{2}{*}{ Ordinance-designated cities } & $\mathrm{OL}$ & 27 & 292.5 & 289.0 & 54 & 300.8 & 300.0 \\
\hline & DN & 240 & 295.7 & 296.5 & 226 & 299.8 & 302.0 \\
\hline \multirow[t]{2}{*}{ Tokyo special wards } & OL & 76 & $325.3 * *$ & $330.0^{* *}$ & 99 & $331.7 * *$ & $332.0^{* *}$ \\
\hline & DML & 144 & 303.3 & 300.0 & 123 & 303.7 & 295.0 \\
\hline \multirow[t]{2}{*}{ Other cities } & $\mathrm{OL}$ & 141 & $299.4 * *$ & $298.0^{* *}$ & 205 & $302.7 * *$ & $301.0 * *$ \\
\hline & DML & 1,853 & 285.0 & 287.0 & 1,816 & 287.5 & 289.0 \\
\hline \multirow[t]{2}{*}{ Towns and villages } & $\mathrm{OL}$ & 35 & $293.1 *$ & $293.0^{*}$ & 53 & $298.9 * *$ & $294.0 * *$ \\
\hline & DML & 512 & 283.0 & 287.5 & 517 & 284.5 & 288.0 \\
\hline
\end{tabular}

\subsection{Results of the cross-sectional analysis concerning Directors}

The results of the cross-sectional analysis of whether the directors held librarian certifications are presented in Table 15. The results of the cross-sectional analysis of whether the directors were working full-time are presented in Table 16. Significant differences were observed between outsourcing and direct management libraries in terms of the extent of library certification as well as full-time versus part-time employment. Table 15 shows that the rate of outsourcing libraries where the director held a librarian certification was significantly higher than that of direct management libraries ( $42.6 \%$ and $21.5 \%$, respectively), based 
Table 12: Results of the cross-sectional analysis of open days (each outsourcing type)

\begin{tabular}{|c|c|c|c|c|c|c|}
\hline & \multicolumn{3}{|c|}{2012 edition } & \multicolumn{3}{|c|}{2015 edition } \\
\hline & $\mathrm{N}$ & Mean & Median & $\mathrm{N}$ & Mean & Median \\
\hline Private enterprise & 193 & $311.2 * *$ & $316.0 * *$ & 311 & $312.6 * *$ & $312.0 * *$ \\
\hline NPO & 34 & $298.0 *$ & $296.0 * *$ & 38 & $300.0 * *$ & $296.5 *$ \\
\hline Public corporation & 46 & 289.7 & $290.0 *$ & 51 & $295.8 * *$ & 291.0 \\
\hline Other organisation & 8 & 277.8 & 292.5 & 15 & $301.9 *$ & $294.0 *$ \\
\hline A Company & 94 & $309.5 * *$ & $306.5 * *$ & 100 & $312.0 * *$ & $303.0 * *$ \\
\hline B Company & 9 & $323.2 * *$ & $323.0 * *$ & 17 & $307.1 *$ & $315.0 * *$ \\
\hline C Foundation & 11 & 294.6 & 290.0 & 11 & $290.4 *$ & 290.0 \\
\hline
\end{tabular}

Table 13: Results of the cross-sectional analysis of whether libraries were open on holidays (each type)

\begin{tabular}{|c|c|c|c|c|c|c|c|}
\hline & \multicolumn{3}{|c|}{2012 edition } & \multicolumn{3}{|c|}{2015 edition } \\
\hline & & $\mathrm{N}$ & No & $\begin{array}{c}\text { Yes } \\
(>=7 \text { days })\end{array}$ & $\mathrm{N}$ & No & $\begin{array}{c}\text { Yes } \\
(>=7 \text { days })\end{array}$ \\
\hline \multirow[t]{2}{*}{ Main libraries } & $\mathrm{OL}$ & 116 & $6.9 \%$ & $88.8 \%$ ** & 154 & $5.8 \%$ & $90.9 \% * *$ \\
\hline & DML & 1,235 & $24.2 \% * *$ & $59.4 \%$ & 1,211 & $20.6 \% * *$ & $64.4 \%$ \\
\hline \multirow[t]{2}{*}{ Annexes } & OL & 183 & $1.1 \%$ & $98.4 \% * *$ & 277 & $3.2 \%$ & $96.4 \% * *$ \\
\hline & DML & 1,684 & $28.0 \% * *$ & $60.8 \%$ & 1,607 & $24.1 \% * *$ & $64.9 \%$ \\
\hline \multirow[t]{2}{*}{ Prefectural library } & OL & 2 & $0.0 \%$ & $100.0 \%$ & 4 & $0.0 \%$ & $100.0 \%$ \\
\hline & DML & 59 & $5.1 \%$ & $86.4 \%$ & 56 & $3.6 \%$ & $87.5 \%$ \\
\hline \multirow{2}{*}{$\begin{array}{l}\text { Ordinance-designated } \\
\text { cities }\end{array}$} & OL & 36 & $0.0 \%$ & $100.0 \% * *$ & 55 & $0.0 \%$ & $100.0 \% * *$ \\
\hline & DML & 243 & $11.5 \%$ & $79.4 \%$ & 226 & $8.8 \% *$ & $84.5 \%$ \\
\hline \multirow[t]{2}{*}{ Tokyo special wards } & OL & 76 & $0.0 \%$ & $100.0 \% * *$ & 99 & $0.0 \%$ & $100.0 \% * *$ \\
\hline & DML & 149 & $7.4 \% *$ & $85.9 \%$ & 124 & $7.3 \% *$ & $84.7 \%$ \\
\hline \multirow[t]{2}{*}{ Other cities } & OL & 146 & $2.7 \%$ & $96.6 \% * *$ & 216 & $4.6 \%$ & $95.4 \% * *$ \\
\hline & DML & 1,911 & $26.8 \% * *$ & $59.3 \%$ & 1,861 & $22.1 \% * *$ & $64.9 \%$ \\
\hline \multirow[t]{2}{*}{ Towns and villages } & OL & 39 & $15.4 \%$ & $71.8 \% * *$ & 57 & $14.0 \%$ & $75.4 \% * *$ \\
\hline & DML & 557 & $39.0 \% * *$ & $45.2 \%$ & 551 & $35.6 \% * *$ & $49.2 \%$ \\
\hline
\end{tabular}

Table 14: Results of the cross-sectional analysis of whether libraries were open on holidays (each outsourcing type)

\begin{tabular}{|c|c|c|c|c|c|c|}
\hline & \multicolumn{3}{|c|}{2012 edition } & \multicolumn{3}{|c|}{2015 edition } \\
\hline & $\mathrm{N}$ & No & $\begin{array}{c}\text { Yes } \\
(>=7 \text { days })\end{array}$ & $\mathrm{N}$ & No & $\begin{array}{c}\text { Yes } \\
(>=7 \text { days })\end{array}$ \\
\hline Private enterprise & 207 & $0.0 \% \dagger \dagger$ & $100.0 \% * *$ & 323 & $0.3 \% \dagger \dagger$ & $99.7 \% * *$ \\
\hline NPO & 36 & $13.9 \%$ & $80.6 \% *$ & 40 & $17.5 \%$ & $77.5 \%$ \\
\hline Public corporation & 47 & $6.4 \% \dagger \dagger$ & $85.1 \% * *$ & 52 & $11.5 \%$ & $80.8 \% *$ \\
\hline Other organisation & 9 & $22.2 \%$ & $77.8 \%$ & 16 & $25.0 \%$ & $75.0 \%$ \\
\hline A Company & 98 & $0.0 \% \dagger \dagger$ & $100.0 \% * *$ & 104 & $0.0 \% \dagger \dagger$ & $100.0 \% * *$ \\
\hline B Company & 9 & $0.0 \%$ & $100.0 \% *$ & 17 & $0.0 \%$ & $100.0 \% * *$ \\
\hline C Foundation & 11 & $0.0 \%$ & $100.0 \% *$ & 11 & $0.0 \%$ & $100.0 \% *$ \\
\hline
\end{tabular}


on the 2012 edition. The rate of outsourcing libraries where the director held a librarian certification was significantly higher than that of direct management libraries $(58.7 \%$ and $25.1 \%$, respectively), based on the 2015 edition. Table 16 shows that the rate of outsourcing libraries where the director worked full-time was $90.2 \%$ whereas that of the direct management libraries was $84.5 \%$ based on the 2012 edition. The rate of outsourcing libraries where the director worked full-time was $91.9 \%$, whereas that of the direct management libraries was $84.9 \%$ based on the 2015 edition. These results suggest that outsourcing libraries tend to have directors who hold librarian certifications and work fulltime when compared to direct management libraries.

The results of the time series analysis are provided in Tables 17 and 18, wherein ' $N$ ' and ' $Y$ ' represent 'No' and 'Yes', respectively. The line of 'NNYY' in Table 17 shows that $31.5 \%$ of the directors of outsourcing libraries did not hold librarian certifications for two years before the introduction of the outsourcing system but did hold librarian certifications in the two years after its introduction, whereas $5.0 \%$ of the directors of direct management libraries did so. On the other hand, the line of 'YYNN' in the Table 17 shows that only $4.2 \%$ of the directors of outsourcing libraries held librarian certifications in the two years before the introduction of the outsourcing system but did not hold librarian certifications in the two years after its introduction. These results suggest that outsourcing libraries tended to employ certified directors after the outsourcing system was introduced.

Further, the line of 'NNYY' in Table 18 shows that $6.3 \%$ of the directors of outsourcing libraries were not working full-time in the two years before the introduction of the outsourcing system but were working full-time in the two years after its introduction, whereas only $2.0 \%$ of the directors of direct management libraries made the transition to full-time work in the same period. The line of 'YYNN' in Table 18 shows that $4.3 \%$ of the directors of outsourcing libraries were working full-time in the two years before the introduction of the outsourcing system but were not working full-time in the two years after its introduction, whereas $1.9 \%$ of the directors of direct management libraries made the same shift.

Table 15: Results of the cross-sectional analysis of whether directors held librarian certifications

\begin{tabular}{lccccccc}
\hline & \multicolumn{3}{c}{2012 edition } & & \multicolumn{3}{c}{2015 edition } \\
\cline { 2 - 4 } \cline { 6 - 8 } & $\mathrm{N}$ & No & Yes & & $\mathrm{N}$ & No & Yes \\
\hline OL & 298 & $57.4 \%$ & $42.6 \% * *$ & & 431 & $41.3 \%$ & $58.7 \% * *$ \\
DML & 2,893 & $78.5 \% * *$ & $21.5 \%$ & & 2,792 & $74.9 \% * *$ & $25.1 \%$ \\
\hline
\end{tabular}

Table 16: Results of the cross-sectional analysis of whether directors worked full-time

\begin{tabular}{lccccccc}
\hline & \multicolumn{3}{c}{ 2012 edition } & & \multicolumn{3}{c}{2015 edition } \\
\cline { 2 - 4 } \cline { 7 - 8 } & $\mathrm{N}$ & No & Yes & & $\mathrm{N}$ & No & Yes \\
\hline OL & 286 & $9.8 \%$ & $90.2 \% *$ & & 419 & $8.1 \%$ & $91.9 \% * *$ \\
DML & 2,890 & $15.5 \% *$ & $84.5 \%$ & & 2,787 & $15.1 \% * *$ & $84.9 \%$ \\
\hline
\end{tabular}

Finally, let us look at the results for each type. Tables 19, 20, 21 and 22 show the results of the investigation of whether directors held librarian certifications and worked full-time. Due to space constraints, we omitted the line if no significant difference was observed for 
Table 17: Results of the time series analysis of whether directors held librarian certifications

\begin{tabular}{lrlrl}
\hline & \multicolumn{2}{c}{ OL } & \multicolumn{2}{c}{ DML } \\
\hline NNNN & $39.3 \%$ & $(140)$ & $66.5 \%$ & $(13,857)$ \\
NNNY & $4.5 \%$ & $(16)$ & $3.1 \%$ & $(647)$ \\
NNYN & $2.5 \%$ & $(9)$ & $1.0 \%$ & $(217)$ \\
NNYY & $31.5 \%$ & $(112)$ & $5.0 \%$ & $(1,051)$ \\
NYNN & $0.3 \%$ & $(1)$ & $0.9 \%$ & $(191)$ \\
NYNY & $0.0 \%$ & $(0)$ & $0.1 \%$ & $(22)$ \\
NYYN & $0.0 \%$ & $(0)$ & $0.6 \%$ & $(125)$ \\
NYYY & $1.4 \%$ & $(5)$ & $1.9 \%$ & $(395)$ \\
YNNN & $0.6 \%$ & $(2)$ & $2.6 \%$ & $(550)$ \\
YNNY & $0.0 \%$ & $(0)$ & $0.3 \%$ & $(57)$ \\
YNYN & $0.0 \%$ & $(0)$ & $0.1 \%$ & $(12)$ \\
YNYY & $1.4 \%$ & $(5)$ & $0.4 \%$ & $(88)$ \\
YYNN & $4.2 \%$ & $(15)$ & $4.4 \%$ & $(908)$ \\
YYNY & $0.3 \%$ & $(1)$ & $0.4 \%$ & $(88)$ \\
YYYN & $1.4 \%$ & $(5)$ & $1.6 \%$ & $(341)$ \\
YYYY & $12.6 \%$ & $(45)$ & $11.0 \%$ & $(2,304)$ \\
\hline
\end{tabular}

Table 18: Results of the time series analysis of whether directors worked full-time

\begin{tabular}{lllrl}
\hline & \multicolumn{2}{c}{ OL } & \multicolumn{2}{c}{ DML } \\
\hline NNNN & $3.2 \%$ & $(11)$ & $10.0 \%$ & $(2,080)$ \\
NNNY & $0.6 \%$ & $(2)$ & $0.7 \%$ & $(152)$ \\
NNYN & $0.0 \%$ & $(0)$ & $0.2 \%$ & $(37)$ \\
NNYY & $6.3 \%$ & $(22)$ & $2.0 \%$ & $(410)$ \\
NYNN & $0.3 \%$ & $(1)$ & $0.2 \%$ & $(34)$ \\
NYNY & $0.3 \%$ & $(1)$ & $0.0 \%$ & $(7)$ \\
NYYN & $0.0 \%$ & $(0)$ & $0.1 \%$ & $(14)$ \\
NYYY & $0.9 \%$ & $(3)$ & $1.2 \%$ & $(253)$ \\
YNNN & $0.0 \%$ & $(0)$ & $1.0 \%$ & $(204)$ \\
YNNY & $0.0 \%$ & $(0)$ & $0.2 \%$ & $(34)$ \\
YNYN & $0.0 \%$ & $(0)$ & $0.0 \%$ & $(0)$ \\
YNYY & $0.9 \%$ & $(3)$ & $0.3 \%$ & $(62)$ \\
YYNN & $4.3 \%$ & $(15)$ & $1.9 \%$ & $(395)$ \\
YYNY & $0.0 \%$ & $(0)$ & $0.3 \%$ & $(64)$ \\
YYYN & $0.3 \%$ & $(1)$ & $1.1 \%$ & $(225)$ \\
YYYY & $83.1 \%$ & $(290)$ & $80.9 \%$ & $(16,825)$ \\
\hline
\end{tabular}


either the 2012 or 2015 edition in 21 and 22 . There was no type under which the number of directors who both held librarian certifications and worked full-time, were higher than those of direct management libraries.

Table 19: Results of the cross-sectional analysis of whether directors held librarian certifications (each type)

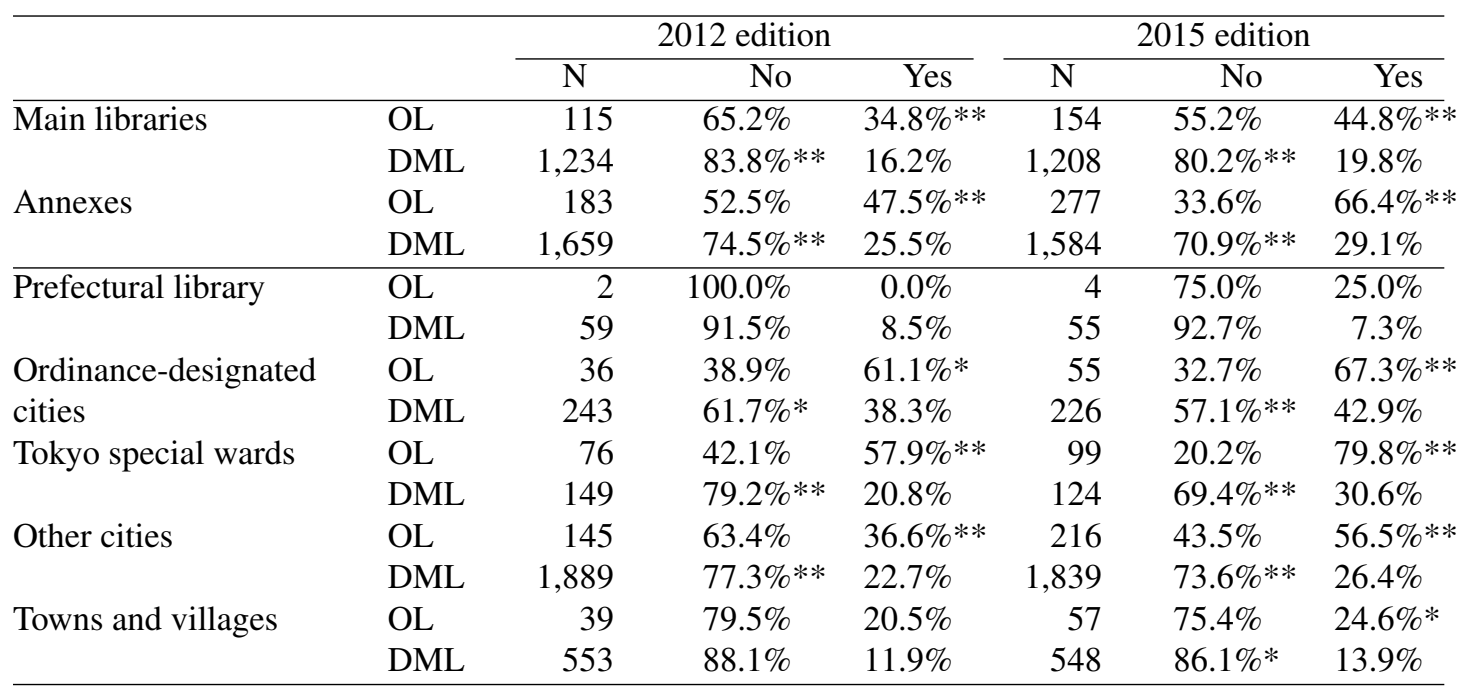

Table 20: Results of the cross-sectional analysis of whether directors held librarian certifications (each outsourcing type)

\begin{tabular}{|c|c|c|c|c|c|c|}
\hline & \multicolumn{3}{|c|}{2012 edition } & \multicolumn{3}{|c|}{2015 edition } \\
\hline & $\mathrm{N}$ & No & Yes & $\mathrm{N}$ & No & Yes \\
\hline$\overline{\text { Privat }}$ & 207 & $51.7 \%+\dagger$ & $48.3 \% * *$ & 323 & $34.1 \%+\dagger$ & $65.9 \% *$ \\
\hline NPO & 36 & $69.4 \%$ & $30.6 \%$ & 40 & $62.5 \%$ & $37.5 \%$ \\
\hline Public corporation & 46 & $73.9 \%$ & $26.1 \%$ & 52 & $71.2 \%$ & $28.8 \%$ \\
\hline Other organizaton & 9 & $55.6 \%$ & $44.4 \%$ & 16 & $37.5 \%+\dagger$ & $62.5 \%$ ** \\
\hline A Company & 98 & $57.1 \%+\dagger$ & $42.9 \% * *$ & 104 & $38.5 \%+\dagger$ & $61.5 \% * *$ \\
\hline $\mathrm{B} \mathrm{Co}$ & 9 & $0.0 \%+\dagger$ & $100.0 \% * *$ & 17 & $11.8 \%+\dagger$ & $88.2 \% *$ \\
\hline C Foundation & 11 & $45.5 \% \dagger$ & $54.5 \% *$ & 11 & $54.5 \%$ & $45.5 \%$ \\
\hline
\end{tabular}

\section{Discussions}

As we mentioned in section 2, many people in Japan including librarians, scholars and politicians have argued that introducing the outsourcing system to public libraries was inappropriate because it had the potential to degrade the quality of library services, decrease the expertise of librarians, and reduce cooperation among libraries. In this section, we focus on these arguments.

The first issue concerns the degradation of the quality of library services. The results of our analysis based on data from Statistics on Libraries in Japan indicated that the introduction 
Table 21: Results of the cross-sectional analysis of whether directors worked full-time (each type)

\begin{tabular}{llccccccc}
\hline & & \multicolumn{3}{c}{2012 edition } & & \multicolumn{3}{c}{2015 edition } \\
\cline { 3 - 5 } \cline { 7 - 8 } & & $\mathrm{N}$ & No & Yes & & N & No & Yes \\
\hline Annexes & OL & 171 & $5.3 \%$ & $94.7 \% * *$ & & 265 & $3.8 \%$ & $96.2 \% * *$ \\
& DML & 1,657 & $14.7 \% * *$ & $85.3 \%$ & & 1,580 & $14.6 \% * *$ & $85.4 \%$ \\
\hline
\end{tabular}

Table 22: Results of the cross-sectional analysis of whether directors worked full-time (each outsourcing type)

\begin{tabular}{lccccccc}
\hline & \multicolumn{3}{c}{ 2012 edition } & & \multicolumn{3}{c}{ 2015 edition } \\
\cline { 2 - 4 } \cline { 6 - 7 } & $\mathrm{N}$ & No & Yes & & $\mathrm{N}$ & No & Yes \\
\hline Private enterprise & 195 & $2.6 \%+\dagger$ & $97.4 \%^{* *}$ & & 311 & $2.9 \%+\dagger$ & $97.1 \% * *$ \\
\hline A Company & 98 & $4.1 \%+\dagger$ & $95.9 \% * *$ & & 104 & $3.8 \%+\dagger$ & $96.2 \% * *$ \\
\hline
\end{tabular}

of the outsourcing system to libraries did not degrade the quality of the services provided. The results of our cross-sectional analysis indicate that outsourcing libraries are open on more number of days than are the direct management libraries, including holidays. The results of the time series analysis also suggest that the number of open days tended to increase after the introduction of outsourcing. On the other hand, the cross-sectional analysis indicated that some forms of usage, such as ILL borrowing, were higher in direct management libraries, and the time series analysis showed that library usage did increase after outsourcing.

Some literature on outsourcing libraries[5][6][7][9] showed that opening hours had expanded and library usage had increased with the introduction of the outsourcing system in some libraries. In this study, the same tendencies were observed, and we can safely say that the tendencies were generally prevalent in outsourcing libraries in Japan.

The second issue is that outsourcing library management decreases the expertise of librarians. However, we found that the designated administrator system did not lead to a decrease in expertise at the least among the directors. The results of our cross-sectional analysis on the directors suggested that a higher number of directors of outsourcing libraries held librarian certifications and worked full-time when compared to the directors of direct management libraries. The results of the time series analysis indicate that outsourcing libraries tended to employ certified directors after the introduction of the outsourcing system.

Nobuta[14][15] clarified that libraries whose directors held librarian certifications tended to perform better, which manifested in many areas such as increased library usage and longer opening hours. From his results, it is possible to infer that the higher usage of and longer opening days at outsourcing libraries may have some relationship with a higher rate of certified directors being employed.

The last issue is that outsourcing libraries will cooperate less with other libraries. Our results indicate that ILL lending and borrowing actually increased after the introduction of outsourcing although the degree of activity may still be under the national average. 
As mentioned earlier, the results of the cross-sectional analysis of library usage suggest that ILL borrowing and lending in direct management libraries were higher than those in outsourcing libraries. However, the results of the time series analysis suggest that library usage, including ILL borrowing and lending, increased after the introduction of outsourcing. ILL services in outsourcing libraries were inactive before the introduction of the outsourcing system. If we assume the rates of ILL borrowing and lending as indexes of cooperation, it can be concluded that cooperation with other libraries was inactive before the introduction of outsourcing and became active afterwards.

We also conducted the same analysis on each library type. However, the tendencies for all libraries mentioned previously hold for most types of libraries (i.e. without depending on library type).

\section{Conclusions}

In this study, we conducted a cross-sectional analysis and a time series analysis with a focus on library usage, open days, and director qualifications and workloads. This study clarified several differences between outsourcing and direct management libraries. The results in this study can be used as basic data for local governments that are considering the introduction of the designated administrator system. This study also found that some arguments opposing the outsourcing system were incorrect. We expect that discussions on outsourcing libraries will become more constructive based on our results.

This study has five limitations: (1) only quantitative analyses were conducted, (2) the cause-effect relationship was not proven, (3) many other library services were left unexamined, (4) library budgets were not investigated, and (5) only the current situation was clarified (tendencies may change). In addition, it would be beneficial for future studies to examine other library services such as those provided to minorities, library budgets, and feelings of satisfaction among users as well as librarians. Through these studies, the appropriateness of switching from direct management to outsourcing libraries can be determined. In addition, Niioka[26] argued about a social 'mission' of public libraries with a focus on outsourcing libraries. Our results clarified some tendency of outsourcing libraries but the service may be cut if the service were judged as inefficient. When we introduce the outsourcing libraries, we should concern about such social mission of public libraries.

\section{References}

[1] Japan Library Association, Statistics on Libraries in Japan 2005-2015 edition, 20062016. (text in Japanese).

[2] Japan Library Association, "About designated administrator system for public libraries," http://www.jla.or.jp/library/tabid/311/Default.aspx. (text in Japanese).

[3] Japan Association for Promotion of Social Education, "Japan association for promotion of social education's View for official documents on designated administrator system on January 25 th, 2005 by ministry of education, culture, sports, science and technology," 2005; http://japse.main.jp/wp-content/uploads/kenkai20050528.pdf. (text in Japanese). 
[4] The Society of study on library problems, "Appeals against adoption of designated administrator system in Public Libraries," July 2006; http://www.jca.apc.org/tomonken/apeal20060711-1.html. (text in Japanese).

[5] T. Maruyama, "Further seriousness of seven-year-old designated administrator: The Yamanakako public library for the people's creativity and the society for digitization of local materials (NPO) and the future of library," Social Education, vol. 65, no. 10, 2010, pp.66-69. (text in Japanese).

[6] H. Yorozuya, "How is regular staffs in the regularization: with the designated administrator," Everyone's library, no. 441, 2014, pp.45-49. (text in Japanese).

[7] H. Maeda, "A Study on the Actual State of Introduction of Designation Administrator System to Public Libraries," Summaries of Technical Papers of Annual Meeting Architectural Institute of Japan. E-1, Architectural Planning and Design I, Building Types and Community Facilities, Planning and Design Method Building Construction System Human Factor Studies Planning and Design Theory 2007, 2007, pp.109-110. (text in Japanese).

[8] Committee on library policies of Japan Library Association, "Results of the questionnaire on introduction of designated management system in libraries," Libraries Today, vol. 45, no. 1, 2007, pp. 41-51. (text in Japanese).

[9] N. Koyama and H. Nagata, "Report on Public Library Management," 2008; http://www.slis.tsukuba.ac.jp/grad/assets/files/project/h19/report.pdf. (text in Japanese).

[10] G. Yamaguchi, "In order to accomplish the purpose of establish, effectively; Public library can develop when local governments have responsibility," Japanese Publications News and Reviews, no. 2461, 2017, pp.4-9.(text in Japanese).

[11] Y. Kambayashi, "Non-regular workers and outsourcing method in public library management," Libraries Today, vol. 47, no. 3, 2009, pp. 145-157. (text in Japanese).

[12] N. Shiomi, "Some thoughts on the present situation of the designated management system," Library Journal, vol. 105, no. 7, 2011, pp.428-431. (text in Japanese).

[13] R. Mouri and I. Ohba, "Desirable capabilities for public library directors in Japan," Library World, vol. 66, no. 5, 2015, pp.326-342. (text in Japanese).

[14] S. Nobuta, "A comparative study of public libraries' management," The Journal of Otemae Women's University, vol. 22, 1988, pp.210-236. (text in Japanese).

[15] S. Nobuta, "Comparative study on public library's activities with the director's librarianship," The Journal of Otemae Women's University, vol. 29, 1995, pp.127-143. (text in Japanese).

[16] T. Watanabe, "Reconsidering the value of reference service in public libraries in Japan," Library and Information Science, no. 66, 2011, pp.153-165. (text in Japanese).

[17] S. Yasuda, "The tracks of reference service for 12 years: from the experience in Toyota city library," Library World, vol. 59, no. 3, 2007, pp.202-209. (text in Japanese). 
[18] Y. Miyakawa, M. Honma, and N. Kanou, "An increase in the total opening hours of university libraries as a consequence of societal needs: relationship with setting up of evening classes," The journal of Information Science and Technology Association, vol. 65, no. 2, 2015, pp.79-82. (text in Japanese).

[19] K. Tsuji, "Investigation on the Elements of Learning Commons that Increase Library Use," Proceedings of the Asia-Pacific Conference on Library \& Information Education \& Practice 2015 (A-LIEP 2015), pp.38-51.

[20] Japan Library Association, "Report about Public Libraries Managed by Designated Administrator System," http://www.jla.or.jp/library/tabid/311/Default.aspx. (text in Japanese).

[21] ILL the acronym of Interlibrary loan and a service whereby a patron of one library can borrow materials that are owned by another library.

[22] Reference Transactions are information consultations in which library staff recommend, interpret, evaluate, and/or use information resources to help others to meet particular information needs (defined by RUSA: A division of the American library association, http://www.ala.org/rusa/guidelines/definitionsreference).

[23] In Japan, city is defined as a municipality that has a population over 50,000 and especially 'ordinance-designated city' is defined as a city that has a population greater than 500,000. 'Tokyo special wards' are 23 municipalities that have highest population density in Japan. Towns and villages are the other municipalities, which are smaller than the others: cities and Tokyo special wards.

[24] Ministry of Internal Affairs and Communications, "Survey on the Introduction of the Designated Administrator System," 2012; http://www.soumu.go.jp/iken/siteikanrisya_dounyujyoukyou_kohyou_h240401.html. (text in Japanese).

[25] H. Minai, "How reference service of libraries should be," The journal of Okinawa library association, no. 9, p.82-103, 2005. (text in Japanese).

[26] S. Niioka, "A Study on the Legal Limitations of Introduction of Designated Administrator System to Public Libraries," Hokkaido University Collection of Scholarly and Academic Papers, Graduate School of Education, vol. 130, p. 133-149, 2018. (text in Japanese). 